\title{
Cutaneous Metastases from Carcinoma of Gall Bladder
}

\author{
Mukhia R, ${ }^{1}$ Shrestha $\mathrm{S}^{1}$ Malla K, ${ }^{2}$ Sharma VK ${ }^{1}$ \\ 'Department of general surgery, NAMS, Bir Hospital ,'Department of pathology , NAMS, Bir Hospital, Kathmandu, \\ Nepal.
}

\section{ABSTRACT}

Cutaneous metastases from internal carcinoma are relatively rare. Metastasis to extremities is still rarer. We report a case of cutaneous metastasis from carcinoma of gall bladder in a 40-year female presenting as a mass in the left lower thigh. The mass was there for four months duration which was progressively growing in size and painful. Mass was $5 \times 7 \mathrm{~cm}^{2}$ in size, mobile, hard and tender. The skin overlying the swelling was eroded with ulcer formation showing sloping edge and slough in the floor. Fine needle aspiration cytology and excisional biopsy revealed a metastatic adenocarcinoma. Cutaneous metastases have been regarded as a bad prognostic indicator.

Key Words: carcinoma of gall bladder, cutaneous metastasis

\section{INTRODUCTION}

Skin metastasis from carcinoma of the gall bladder is extremely rare and its incidence varies from 0.7 to $9 \%{ }^{1}$ It is usually detected around surgical scars but it is rare to have distant metastasis to extremities. It occurs late in the course of disease. There are direct, lymphatic, vascular, neural, intraperitoneal and intraductal dissemination from carcinoma of gall bladder. Liver and lymph nodes are the two most common sites of dissemination. ${ }^{2}$ The most common tumors to metastasize to the skin are breast, lung, colorectal, renal and ovarian carcinomas. $^{3}$

\section{CASE REPORT}

A 40-year female presented with a mass in lower back of the left thigh for four months which was progressive and painful. Mass was $5 \times 7 \mathrm{~cm}^{2}$ in size, mobile, hard and tender. The skin overlying the swelling was eroded with ulcer formation showing sloping edge and slough in the floor (Figure 1). Inguinal lymph nodes were not enlarged. She was diagnosed to have inoperable stage four poorly differentiated adenocarcinoma of gall bladder. She had undergone palliative gastrojejunostomy and was being treated with radiotherapy.

\section{Correspondence: \\ Dr. Rupesh Mukhia \\ Department of General Surgery \\ National Academy of Medical Sciences \\ Bir Hospital, Kathmandu, Nepal. \\ Email: rupeshmukhia@hotmail.com \\ Phone: 977-9841210437}


Haematological investigations were within normal range. Her X-ray of chest and left thigh were normal. Fine needle aspiration cytology (FNAC) of the mass revealed it to be metastatic adenocarcinoma. Excisional biopsy was performed with $1 \mathrm{~cm}$ of normal margin all around the lesion and defect was closed primarily.

Histopathological finding showed tumour cells arranged in poorly formed glandular and in tubular pattern infiltrating into the fibro-collagenous tissue (Figure 2). Nuclei of cells were moderately pleomorphic containing round to oval nuclei having abundant cytoplasm. Some of nuclei showed prominent nucleoli. Occasional mitotic figures were also noted. Hence impression was made as Metastatic Adenocarcinoma.

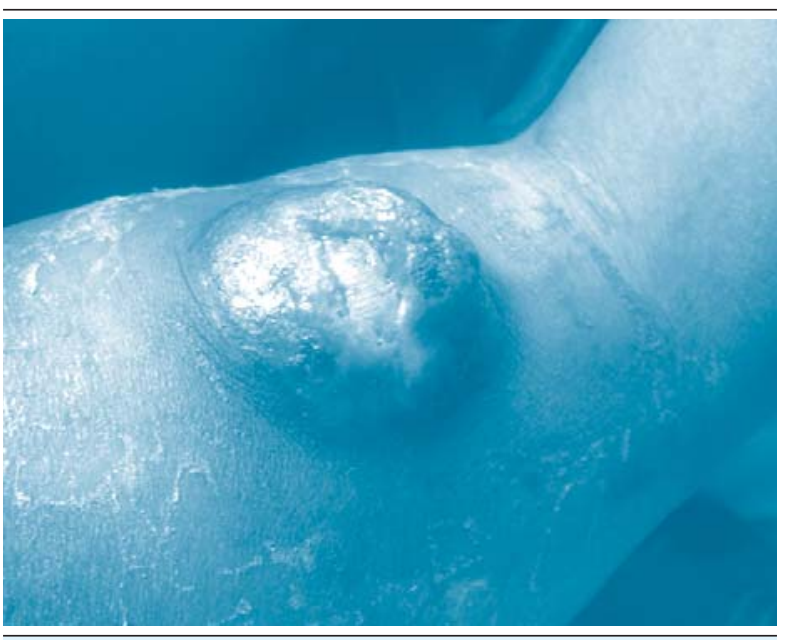

Figure 1. Mass in lower back of the left thigh

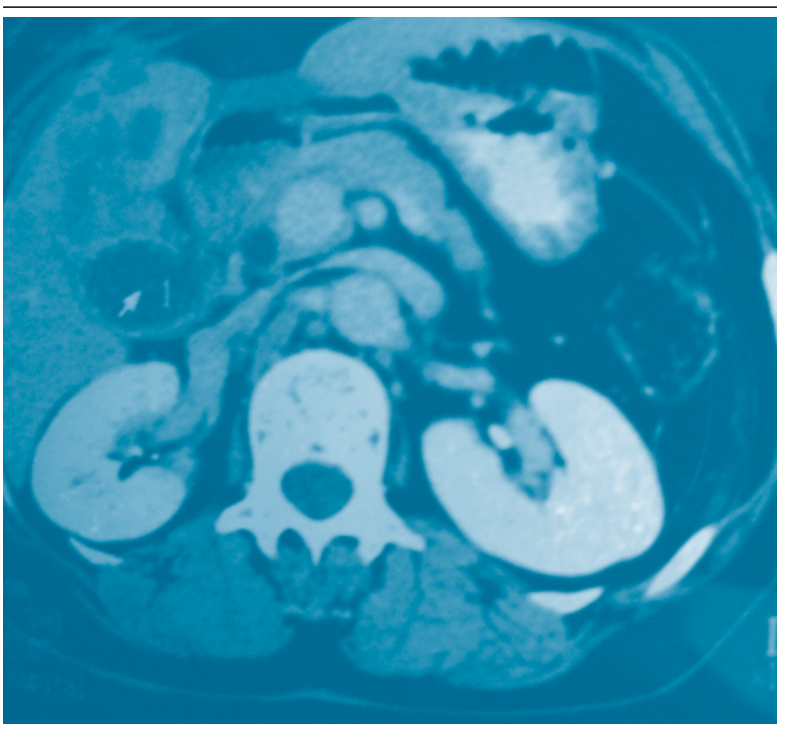

Figure 3. Contrast Enhanced CT of abdomen: Gall bladder mass with involvement of liver, omentum and surrounding structures

\section{DISCUSSION}

Breast carcinoma in female is the most frequent primary tumour to metastasize to the skin consisting $24 \%$ of all cutaneous metastasis. ${ }^{3}$ Its overall incidence has been reported to be $5 \%$ by one meta analysis study. ${ }^{3}$ In men, most common carcinoma to metastasize to skin is the carcinoma of the lung. ${ }^{3}$ Primary carcinoma of gall bladder spreads either by direct extension or metastases. Direct extension occurs through perivascular or perineural mode. Liver is commonly involved in direct extension in $60 \%$ to $90 \%$. ${ }^{4}$ Other organs commonly affected are the bile ducts, duodenum, stomach, colon, omentum, abdominal wall, pancreas and portal vein. Extra-abdominal metastasis is rare and the lung is most common site. ${ }^{4}$

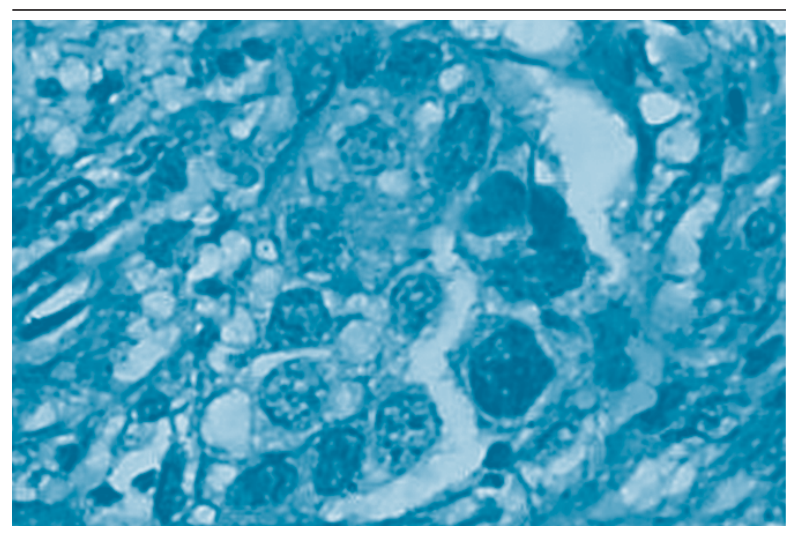

Figure 2. Histopathological features of excisional biopsy of the mass

Carcinoma of gall bladder has very rare potential for skin metastasis. ${ }^{1-3}$ In the English literature, there have only been seven reports of metastasis from cancer of the gallbladder to the skin. ${ }^{5}$ These areas included upper lip, upper arm, preauricular area, scalp, neck and back. It shows that most common sites of cutaneous metastases are the neck and head and the trunk. Cases have been reported to have umbilical metastasis known as Sister Mary Joseph nodule from carcinoma of gall bladder. ${ }^{6}$ Krunic et al has reported metastasis to scalp and face from signet ring carcinoma of gall bladder after resection of carcinoma. ${ }^{7}$ Metastases on the limbs are even rarer. ${ }^{8}$ Metastasis to lower limb has not been reported so far. Cutaneous metastases has been regarded as a bad prognostic indicator with an average survival time of 7.5 months. $^{9}$

Cutaneous metastasis usually doesn't cause any severe problem but it is a sign of systematic spread of disease. It typically presents as asymptomatic cutaneous or subcutaneous nodules. It may present inflammatory pattern mimicking cellulitis or other morphologies as erythema annulare, condyloma, herpes zoster, epidermal inclusion cyst and an ulcer. ${ }^{9}$ 
Confirmation of cutaneous metastasis can be challenging High-resolution and colour Doppler sonography can be helpful in evaluation of skin metastasis. ${ }^{10}$ Hypoechoic irregular nodules with high vascularity are highly suspicious of metastasis. Histopathologic examination can be accomplished by immunostaining. Fine needle aspiration cytology (FNAC) may be used as a minimal invasive diagnostic tool. Complete excision is the method of choice to achieve diagnostic accuracy. In the present case, diagnosis was established through FNAC and excision biopsy. It shows that gall bladder cancer can be aggressive in nature.

\section{REFERENCES}

1. Kaur J, Puri T, Julka PK, Gunabushanam G, Iyer VK, Singh $\mathrm{MK}$, et al. Adenocarcinoma of the gall bladder presenting with a cutaneous metastasis. Indian J Dermatol Venereol Leprol. 2006;72:64-6.

2. Suganuma M, Marugami Y, Sakurai $Y$, Ochiai M, Hasegawa $\mathrm{S}$, Imazu H, et al. Cardiac metastasis from squamous cell carcinoma of gallbladder. J Gastroentero. 1997;32:852-6.

3. Krathen RA, Orengo IF, Rosen T. Cutaneous metastasis: a meta-analysis of data. South Med J. 2003;96:164-7.

4. Garg PK, Khurana N, Hadke NS. Subcutaneous and breast metastasis from asymptomatic gall bladder carcinoma. Hepatobiliary Pancreat Dis Int. 2009;8:209-11.

5. Bardaji M, Roset F, Puig A, Badal J, Fernandez-Lavos MJ. Cutaneous metastatic adenocarcinoma of gallbladder origin: report of a case and review of the literature. Hepatogastroenterology. 1998;44(22):930-1.
6. Renner R, Sticherling M. Sister Mary Joseph's nodule as a metastasis of gall bladder carcinoma. Int J Dermatol. 2007;46(5):505-7.

7. Krunic AL, Chen HM, Lopatka K. Signet cell carcinoma of gall bladder with skin metastasis. Australas J Dermatol. 2007;48(3):187-9

8. Lin CY, Lee CT, Huang JS, Chang LC. Transitional cell carcinoma metastasis to arm skin from the renal pelvis. Chang Gung Med J. 2003;26:525-9.

9. Saeed S, Keehn CA, Morgan MB. Cutaneous metastasis: a clinical, pathological and immunohistochemical appraisal. J Cutan Pathol. 2004;31:419-30.

10. Giovagnorio F, Valentini C, Paonessa A. High-resolution and color Doppler sonography in the evaluation of skin metastases. J Ultrasound Med. 2003;22:1017-22. 